\title{
Effect of Temperature and Gamma-Ray Irradiation on Optical Characteristics of Fiber Bragg Grating Inscribed Radiation-Resistant Optical Fiber
}

\author{
Seongmin $\mathrm{JU}^{1}$, Youngwoong $\mathrm{KIM}^{2}$, Kadathala LINGANNA², \\ Yune Hyoun $\mathrm{KIM}^{2}$, and Won-Taek $\mathrm{HAN}^{1 *}$
}

\begin{abstract}
${ }^{1}$ School of Electrical Engineering and Computer Science, Gwangju Institute of Science and Technology, Gwangju 61005, South Korea

${ }^{2}$ Smart Photonics Research Center/Advanced Optical Lens Research Center/Laser Research Center, Korea Photonics Technology Institute, Gwangju 61007, South Korea
\end{abstract}

${ }^{*}$ Corresponding author: Won-Taek HAN_ E-mail: wthan@gist.ac.kr

\begin{abstract}
A new radiation-hard germano-silicate glass optical fiber with a pure silica glass buffer and a boron-doped silica glass inner cladding was fabricated for temperature sensor application based on the fiber Bragg grating (FBG) under $\gamma$-ray irradiation environment. The temperature dependences of optical attenuation at $1550.5 \mathrm{~nm}$ and Bragg reflection wavelength shift from $18{ }^{\circ} \mathrm{C}$ to $40{ }^{\circ} \mathrm{C}$ before the $\gamma$-ray irradiation were about $4.57 \times 10^{-4} \mathrm{~dB} /{ }^{\circ} \mathrm{C}$ and $5.48 \mathrm{pm} /{ }^{\circ} \mathrm{C}$, respectively. The radiation-induced optical attenuation at $1550.5 \mathrm{~nm}$ and the radiation-induced Bragg reflection wavelength shift under the $\gamma$-ray irradiation with the total dose of $22.85 \mathrm{kGy}$ at $35^{\circ} \mathrm{C}$ were about $0.03 \mathrm{~dB} / \mathrm{m}$ and $0.12 \mathrm{~nm}$, respectively, with the $\gamma$-ray irradiation sensitivity of $5.25 \times 10^{-3} \mathrm{pm} / \mathrm{Gy}$. The temperature and the $\gamma$-ray irradiation dependence of optical attenuation at $1550.5 \mathrm{~nm}$ in the FBG written fiber with boron-doped silica glass inner cladding were about 6 times and 4 times lower than that in the FBG written fiber without boron-doped silica glass inner cladding under a temperature change from $18{ }^{\circ} \mathrm{C}$ to $40{ }^{\circ} \mathrm{C}$ and the $\gamma$-ray irradiation with the total dose of $22.85 \mathrm{kGy}$ at $35^{\circ} \mathrm{C}$, respectively. Furthermore, the effect of temperature increase on the Bragg reflection wavelength of the FBG written fiber with boron-doped silica inner cladding was much larger about 1000 times than that of the $\gamma$-ray irradiation. However, no influence on the reflection power of the Bragg wavelengths and the full width at half maximum (FWHM) bandwidth under temperature and the $\gamma$-ray irradiation change was found. Also, after the $\gamma$-ray irradiation with the dose of $22.85 \mathrm{kGy}$, no significant change in the refractive index was found but the residual stresses developed in the fiber were slightly relaxed or retained.
\end{abstract}

Keywords: Optical fiber; radiation resistance; temperature sensor; fiber Bragg grating; radiation-induced attenuation

Citation: Seongmin JU, Youngwoong KIM, Kadathala LINGANNA, Yune Hyoun KIM, and Won-Taek HAN, "Effect of Temperature and Gamma-Ray Irradiation on Optical Characteristics of Fiber Bragg Grating Inscribed Radiation-Resistant Optical Fiber," Photonic Sensors, 2020, 10(1): 16-33.

\section{Introduction}

Real-time monitoring for stable usage of nuclear power using the optical fiber sensing technology has drawn much attention in the nuclear industry due to the excellent durability of the optical fiber in the

Received: 13 January 2019 / Revised: 9 July 2019

(C) The Author(s) 2019. This article is published with open access at Springerlink.com

DOI: 10.1007/s13320-019-0567-4

Article type: Regular 
irradiation environment [1-9]. Especially, the optical fiber based on the fiber Bragg grating (FBG) as a sensing probe has come into the spotlight in the control systems of the nuclear reactor and the nuclear power plant, mainly due to the advantages of electromagnetic interferences immunity, remote metering, multiplexing capabilities, and fast response [10-15]. However, the irradiation with gamma-ray ( $\gamma$-ray) on the optical fiber with the FBG is known to bring about an increase in the transmission loss and thus the shift of the Bragg peak wavelength [11-20]. An increase in the signal transmission loss under high energy irradiation is known due to the formation of radiation-induced defects and color centers [1-13, 21-23].

Thus, the radiation resistance can be improved by reducing and blocking the formation of radiation-induced defects such as non-bridging oxygen hole centers (NBOHCs), $\mathrm{E}^{\prime}$ centers, and self-trapped holes (STHs) [5-8, 18, 19, 22-25]. Also, the radiation resistance of glass optical fibers depends on glass composition as well as its manufacturing process. The radiation resistance can be increased by changing the composition of glass or decreasing the residual stress in fiber core [26]. When boron (B) is added in silica glass cladding, the formation of defect centers is known to be minimized by forming other stable B-related color centers such as the boron oxygen hole centers (BOHCs) and boron $\mathrm{E}^{\prime}$ center [27, 28]. Moreover, the presence of $\mathrm{B}$ in the depressed-index inner cladding helps increase the bend-insensitivity [29]. However, this change in the composition of the cladding alters the refractive index and residual stress of the fiber, too. Another way to increase the radiation resistance is to put a buffer layer of pure silica glass between the Ge-doped silica glass core and the B-doped cladding because the radiation resistance in glasses is first of all achieved by selecting a glass material as pure as possible [30]. In addition, the silica glass buffer layer can minimize the variation from the difference in thermal expansion between the core and cladding.
On the other hand, most of the radiation-resistant glass fibers do not contain germanium dioxide $\left(\mathrm{GeO}_{2}\right)$ in the core and thus no germanium (Ge)-related defects are formed by $\gamma$-ray irradiation. But these fibers are not appropriate to be used as an FBG based fiber sensor probe because of its low photosensitivity for FBG inscription upon ultra-violet (UV) laser exposure [4-8, 18-23, 26, 31, 32]. Instead, a pure or F-doped silica core glass fibers are used for the FBG inscription using the femtosecond (fs) infra-red (IR) laser [17, 18, 20, 21]. The peak wavelength of FBG is known to shift by the $\gamma$-ray irradiation and the reported shift values vary from tens to several hundreds of pico-meters under the dose in the $100 \mathrm{kGy}$ range $[12,13,15]$. The merit of the FBG based fiber sensor is its insensitivity to the radiation-induced loss because the information of the measured parameters such as temperature, bend, or strain is only wavelength-dependent. However, when the fiber is exposed to high dose $\gamma$-ray irradiation, the transmission is highly attenuated and the resonant wavelength is hard to define.

In this paper, we fabricated a novel radiation-hard germano-silicate glass fiber with a pure silica glass buffer and a B-doped silica glass inner cladding. To investigate the effect of temperature and $\gamma$-ray irradiation on the optical attenuation, FBG was inscribed on the fiber and its wavelength shift was measured at various temperatures. The dependences of the radiationinduced attenuation (RIA) on the dose-rate and the radiation-induced Bragg reflection wavelength (RIBRW) shift were measured before, during, and after the $\gamma$-ray irradiation at $35{ }^{\circ} \mathrm{C}$. The effect of the $\gamma$-ray irradiation on refractive index and residual stress of the fiber were also investigated.

\section{Experiment}

\subsection{Fabrication of the fiber}

A preform of germano-silicate glass optical fiber with a pure silica glass buffer and a B-doped silica 
glass inner cladding (denoted as the buffered fiber) was fabricated by using the outside vapor deposition (OVD) and the modified chemical vapor deposition (MCVD) process [33]. For the core of the preform, Ge doped silica glass layers were deposited by the OVD process using silicon tetrachloride $\left(\mathrm{SiCl}_{4}\right)$ and germanium tetrachloride $\left(\mathrm{GeCl}_{4}\right)$ with oxygen $\left(\mathrm{O}_{2}\right)$ as a carrier gas. To minimize inevitable residual stresses in the fiber core and at the interface of the core and the cladding due to their different thermal expansions, buffer layers of pure silica glass were also deposited on the outside of the core. Next, the B-doped silica glass inner cladding was deposited to build a depressed-index layer onto the inner surface of a fused silica glass tube (GE Quartz, code \#214) as a substrate for the outer cladding of the preform by the MCVD process. Note that the concentration of hydroxyl $(\mathrm{OH})$ groups in the fused silica glass tube was very low under $5 \mathrm{ppm}$.

The fused silica glass tube with the depressed-index inner cladding layer was collapsed and jacketed with the prepared germano-silicate glass core rod with the pure silica glass buffer layers, which was fabricated by the OVD process, to form a final preform. Therefore, the buffer layers of the pure silica glass were located between the core and the depressed-index inner cladding. For a comparison, the same germano-silicate glass optical fiber with pure silica glass buffer layers made by the OVD process but without a B-doped silica glass inner cladding was fabricated as a reference. Finally, both preforms were drawn into fibers with $125 \mu \mathrm{m}$ in outer diameter by using the draw tower at $2150{ }^{\circ} \mathrm{C}$. The preform down-feed speed and the capstan winding speed were about $1 \mathrm{~mm} / \mathrm{min}$ and $20 \mathrm{~m} / \mathrm{min}$, respectively.

The core diameter and the cut-off wavelength of the fabricated buffered fiber were $8.56 \mu \mathrm{m}$ and $1225 \mathrm{~nm}$, respectively. The width of the buffer and the depressed-index inner cladding were $8.92 \mu \mathrm{m}$ and $9.38 \mu \mathrm{m}$, respectively. The refractive index differences between the core and the buffer $\left(\Delta n_{\text {core }}\right)$, and between the buffer and the depressed-index inner cladding ( $\left.\Delta n_{\text {depressed-index }}\right)$ were 0.0061 and -0.0059 , respectively. The concentrations of $\mathrm{GeO}_{2}$ and $\mathrm{B}$ in the fiber core and inner cladding were estimated from the refractive index profile to be 3.8 mole $\%$ and 18.5 mole $\%$, respectively [34-36]. For a comparison, the core diameter and the cut-off wavelength of the reference fiber were $9.50 \mu \mathrm{m}$ and $1190 \mathrm{~nm}$, respectively. The concentration of $\mathrm{GeO}_{2}$ in the reference fiber was estimated from the refractive index profile $\left(\Delta n_{\text {core }}=0.0064\right)$ to be 4.1 mole $\%$. Figure 1 shows the schematic diagram of the cross-section with the refractive index profile of the buffered fiber.

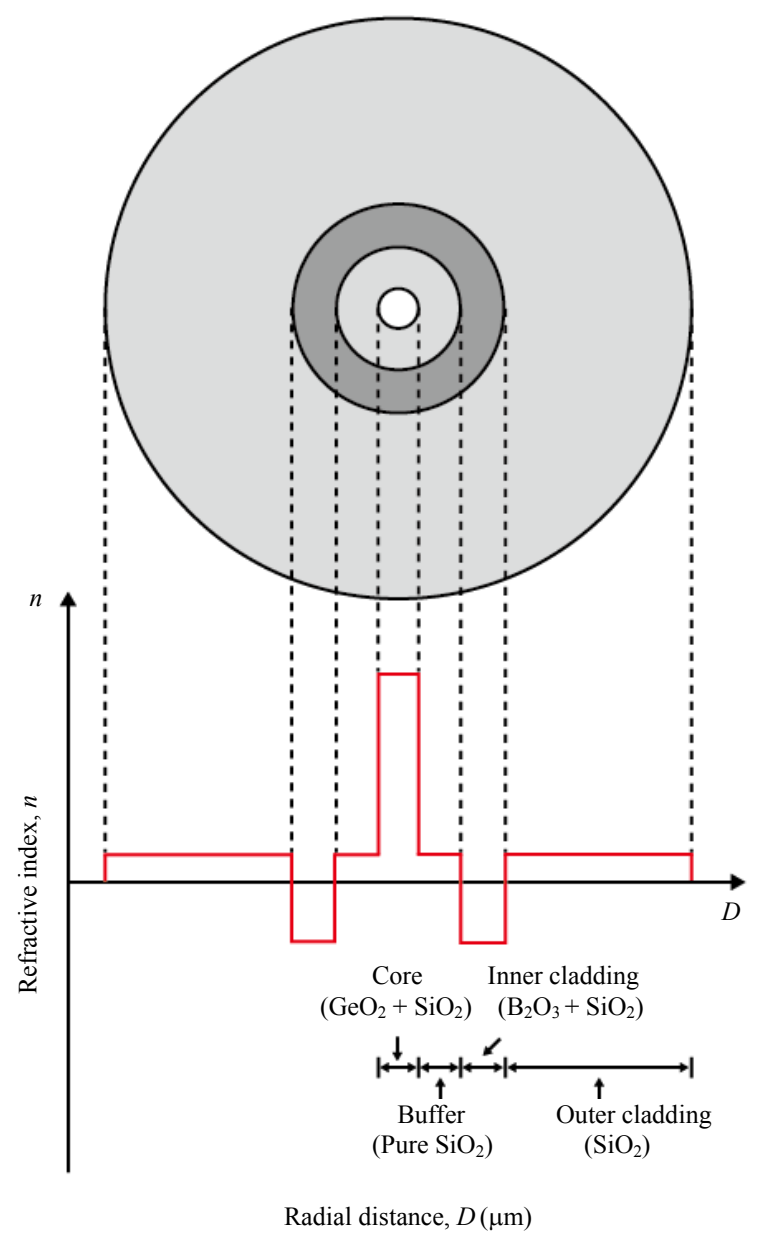

Fig. 1 Schematic diagram of the cross-section with the refractive index profile of the buffered fiber.

\subsection{Fabrication of the fiber Bragg grating}

FBG as a sensor probe was inscribed onto the fabricated fibers. To facilitate FBG formation by increasing photosensitivity of the fibers, the 
hydrogen loading process was carried out under the pressure of 100 bars at room temperature for 96 hours. Note that both the buffered fiber and the reference fiber were pre-irradiated under the $\gamma$-ray irradiation of $7.20 \mathrm{kGy}$ to relieve the strained $\mathrm{Si}-\mathrm{O}$ or Ge-O bonds formed during the fiber fabrication process before the FBG inscription. FBGs were written on the stripped portion of the fibers by using a phase mask (QPS Photronics Inc.) of peak reflection near $1550 \mathrm{~nm}$ by the $\mathrm{KrF}$ excimer laser at $248 \mathrm{~nm}$. The fibers with the FBG (denoted as the FBG buffered fiber and the FBG reference fiber) were then annealed at $80{ }^{\circ} \mathrm{C}$ for 10 hours to release weak photo-induced changes from hydrogen molecules penetrated through the optical fiber core during the hydrogen loading process [10, 37]. Then the FBG fibers were recoated with acrylate resin and cured with UV light, where the length of the FBG and the recoated region were $10 \mathrm{~mm}$ and $20 \mathrm{~mm}$, respectively.

\subsection{Measurement}

Optical attenuation of the fabricated buffered and the reference fibers before and after the $\gamma$-ray irradiation was measured by the cut-back method where the white light source (WLS, Ando AQ 4303B) was used for launching the input broadband light and the output spectrum was obtained with the optical spectrum analyzer (OSA, Ando AQ 6315B). Also, to investigate the effects of the $\gamma$-ray irradiation on refractive index and residual stress before and after the irradiation, the refractive index and stress profile of the fibers were also measured by the fiber index profiler (Interfiber Analyzer, IFA-100). The $\gamma$-ray irradiation was carried out onto the fibers by a ${ }^{60} \mathrm{Co} \gamma$-ray (MSD Nordion, pencil type/C-188 sealed). In addition, the existence and distribution of dopants in the fiber were verified by the electron probe micro-analyzer (EPMA, Shimadzu EPMA-1600). Optical transmission was measured to investigate the dependence of $\gamma$-ray dose-rate of the buffered and reference fibers with the FBG on RIA by using the OSA (Ando AQ6317B) together with the amplified spontaneous emission source (ASE source, Optoware-B200) operating around $1550 \mathrm{~nm}$ as an input light source. The RIA and the RIBRW shift were calculated from the difference of optical output powers and Bragg reflection peak wavelengths, respectively before and after the irradiation within the length of the exposed fiber.

The fibers with the FBGs inscribed in the middle of the total length of 11 meters were irradiated by the ${ }^{60} \mathrm{Co} \gamma$-ray until total dose of $22.85 \mathrm{kGy}$, which was the maximum irradiation dose per hour of our irradiation facility, at stabilized temperature of $35 \pm 0.1{ }^{\circ} \mathrm{C}$ in an electric temperature chamber having a $\gamma$-ray transmission silica glass window. Note that in order to eliminate the cross-sensitivity between temperature and radiation due to the radiation-induced temperature changes, the temperature higher than room temperature at $35^{\circ} \mathrm{C}$ was selected which did not respond to an increase in the radiation dose. Thus, it is possible to measure the change of the FBG characteristics according to the radiation change without the influence of the temperature change. The RIA and the RIBRW shift of FBG were measured for 124 minutes with the time interval of 3 minutes during the $\gamma$-ray irradiation, which were continuously measured even after terminating the $\gamma$-ray irradiation for 100 minutes with $3-5$ minutes of time interval. Note that to investigate the effect of the $\gamma$-ray irradiation on the optical attenuation, refractive index, residual stress, and the existence and distribution of dopants, the irradiation of the fibers was carried out at the total dose $22.85 \mathrm{kGy}$ for 60 minutes at room temperature. But in the case using the electric temperature chamber, the time of the $\gamma$-ray irradiation increased to 124 minutes to compensate the decrease in irradiation due to the radiation shielding from the electric temperature chamber.

The FBGs inscribed fibers were placed side by side facing the $\gamma$-ray source for exposing the uniform $\gamma$-ray dose along the fibers. The dose-rate of 
the $\gamma$-ray irradiation was measured by using the alanine pellet dosimeter and was estimated by the electron paramagnetic resonance (EPR) analysis with the BRUKER's e-scan alanine dosimetry Control room system. The measurement setup (a) and the temperature profiles and the events of the $\gamma$-ray irradiation during the measurements (b) are shown in Fig. 2.

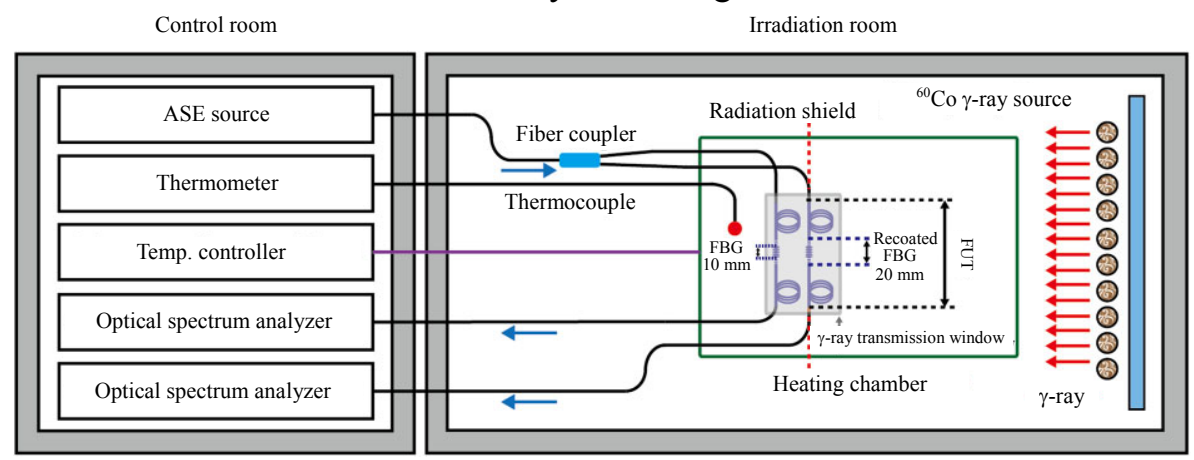

(a)

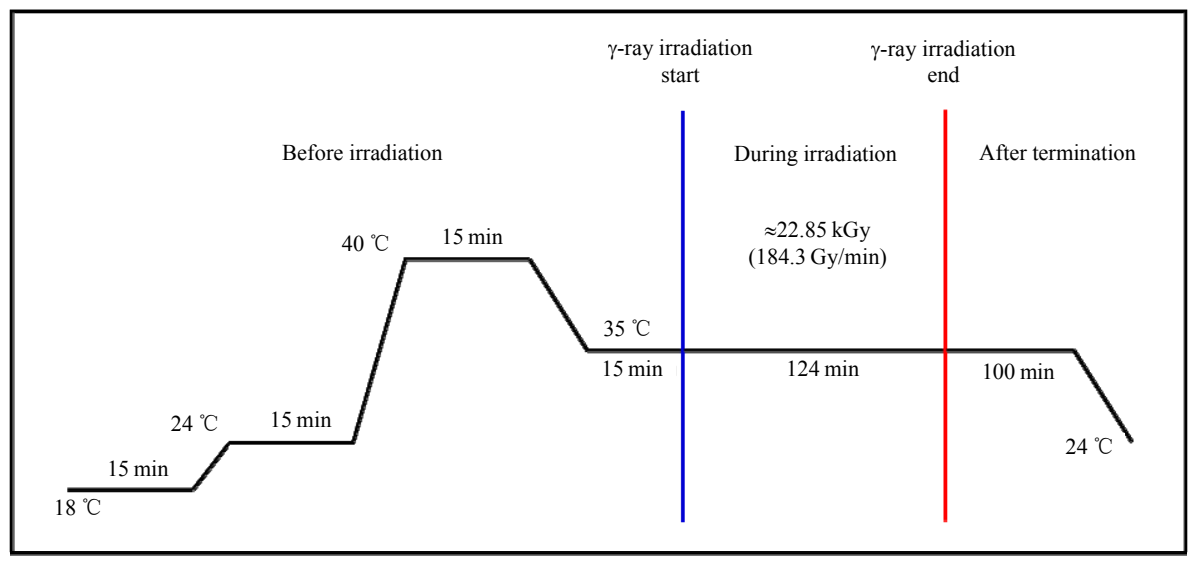

(b)

Fig. 2 RIA measurement of (a) the experimental setup upon the $\gamma$-ray irradiation and (b) the temperature profile with the events of the $\gamma$-ray irradiation during the measurements.

\section{Results}

Figure 3 compares the refractive index difference and the residual stress measured from a cross-section of the buffered fiber before and after the irradiation with total dose of $22.85 \mathrm{kGy}$. The fiber core and the inner cladding showed a higher $\left(\Delta n_{\text {core }}=\right.$ $0.0061)$ and lower $\left(\Delta n_{\text {depressed-index }}=-0.0059\right)$ refractive index than the buffer and the outer cladding due to the presence of $\mathrm{GeO}_{2}$ and $\mathrm{B}$, respectively, as shown in Fig. 3(a) [3, 38].

To investigate the effect of $\gamma$-ray irradiation on residual stress of the fibers, residual stresses of the fibers before and after the $\gamma$-ray irradiation were estimated by measuring the phase difference between the two orthogonally polarized light beams, as shown in Fig. 3(b) [39]. When the buffered fiber preform was drawn into the fiber at high temperature, most of the drawing tension was applied to the outer cladding due to the relatively high viscosity, resulting in the tensile residual stress on the outer cladding and the balanced compressive stress on the outermost cladding. The tensile stress was formed on the inner cladding containing B due to its still positive thermal expansion coefficient even though the refractive index was lowered due to B. But the compressive stresses in the buffer and the buffer-inner cladding boundary were induced by the mechanical stress due to the difference in the viscoelastic properties of the different regions during 
the cooling of the fiber. The fiber core with tensile stress was due to the thermal stress induced by an increase in the thermal expansion coefficient caused by adding $\mathrm{GeO}_{2}$ to $\mathrm{SiO}_{2}$ [40]. Note that most of the compressive stress in the center of the core resulted from the mechanical stress induced by a decrease in viscosity by $\mathrm{GeO}_{2}$ than that from the thermal stress [41]. The residual stresses of the center of the core, the outer section of the core, the buffer cladding, the

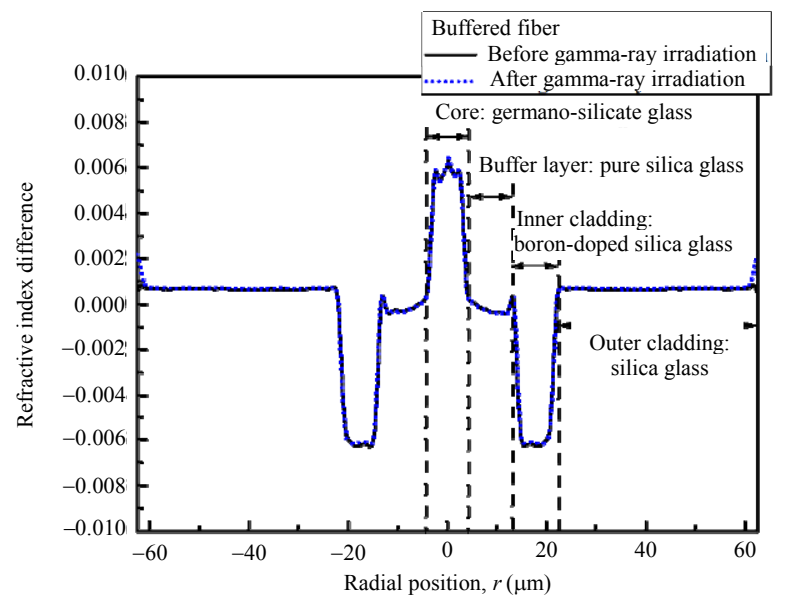

(a) core-buffer boundary, the inner cladding, the buffer-inner cladding boundary, the outer cladding, and the outermost cladding of the buffered fiber before the $\gamma$-ray irradiation were found to be under a compression of $-4.3 \mathrm{MPa}$, a tension of $21.8 \mathrm{MPa}$, a compression of $-3.8 \mathrm{MPa}$, a compression of $-5.7 \mathrm{MPa}$, a tension of $24.6 \mathrm{MPa}$, a compression of $-26.2 \mathrm{MPa}$, a tension of $6.2 \mathrm{MPa}$, and a compression of $-24.3 \mathrm{MPa}$, respectively.

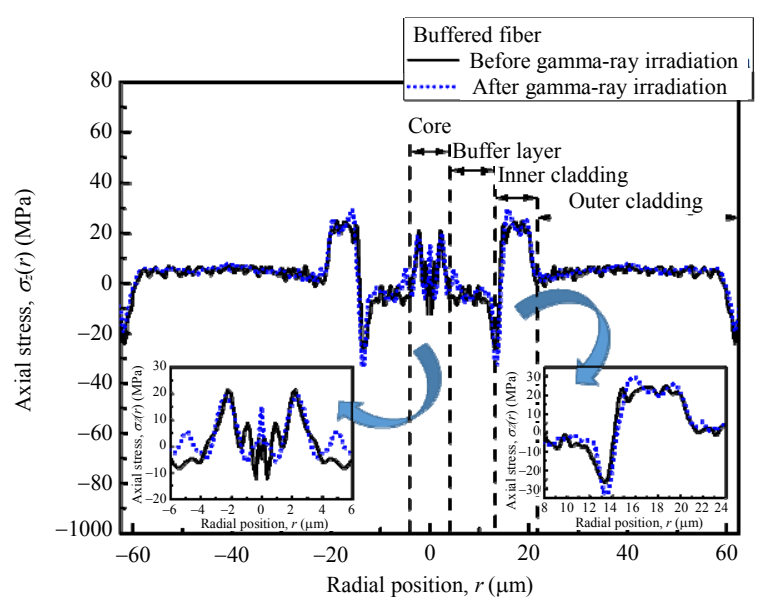

(b)

Fig. 3 Radial profiles of (a) refractive index and (b) residual stress of the buffered fiber before and after the $\gamma$-ray irradiation with the total dose of $22.85 \mathrm{kGy}$ at room temperature in air (the inset image shows the enlarged residual stresses in the core and inner cladding regions).

After the $\gamma$-ray irradiation at the total dose of $22.85 \mathrm{kGy}$ onto the fiber, no significant change in the refractive index was found in an accuracy of $\pm 1 \times 10^{-4}$ as shown in Fig. 3(a). In the case of the residual stress after the $\gamma$-ray irradiation, while the compressive stress in the buffer cladding and the outermost cladding region was slightly relaxed from $-3.8 \mathrm{MPa}$ to $-2.6 \mathrm{MPa}$ and from $-24.3 \mathrm{MPa}$ to $-21.6 \mathrm{MPa}$, respectively, the compressive stress in the boundary between the buffer and inner cladding increased from $-26.2 \mathrm{MPa}$ to $-33.9 \mathrm{MPa}$. The tensile stress in the B-doped inner cladding slightly increased from $24.6 \mathrm{MPa}$ to $25.9 \mathrm{MPa}$ without the change of tensile stress of $6.2 \mathrm{MPa}$ in the outer cladding region. It is interesting to note that as the compressive stress in the core center and at the core-buffer boundary had changed to tensile stress from $-4.3 \mathrm{MPa}$ to $15.3 \mathrm{MPa}$ and from
$-5.7 \mathrm{MPa}$ to $5.9 \mathrm{MPa}$, respectively, the tensile stress around the center was relaxed from $21.8 \mathrm{MPa}$ to 19.1 MPa as shown in the inset image of Fig. 3(b). The measured residual stresses of the buffered and reference fibers before and after the $\gamma$-ray irradiation of $22.85 \mathrm{kGy}$ are summarized in Table 1.

Figure 4 shows the distribution of dopants in the cross section of the buffered fiber obtained by the EPMA mapping analysis before and after the $\gamma$-ray irradiation. The buffered fiber showed the distinct images of the core, the inner cladding, the core-buffer boundary, and the buffer-inner cladding boundary and the presence of $\mathrm{GeO}_{2}$ and $\mathrm{B}$ in the core and the inner cladding was clearly distinguished. The layer between the core and the inner cladding was the buffer of pure silica glass. $\mathrm{GeO}_{2}$ and $\mathrm{B}$ distribution from the EPMA analysis 
was almost similar to those from the refractive index profile [Fig.3(a)]. From the EPMA based image, the core diameter, the width of the buffer, and the width of the average depressed-index of the inner cladding were $9.17 \mu \mathrm{m}, 11.59 \mu \mathrm{m}$, and $5.55 \mu \mathrm{m}$, respectively. Some differences in the core diameter, the width of the buffer, and the width of the depressed-index cladding between both the measured refractive index and the EPMA image may be due to the back-scatter electron imaging (BSE) contrast difference. Note that the boundary of the buffer and the inner cladding could not be identified due to the low concentration of $\mathrm{B}$ by the EPMA. The most important thing is that no change in the distribution of $\mathrm{GeO}_{2}$ and $\mathrm{B}$ after the $\gamma$-ray irradiation was found in this limit of the resolution. A little asymmetry of the inner cladding was due to the instability of rotation of the silica glass tube with the layers upon consolidation at high temperature during the MCVD process.

Table 1 Residual stresses of the buffered and the reference fibers before and after the $\gamma$-ray irradiation of $22.85 \mathrm{kGy}$.

\begin{tabular}{|c|c|c|c|c|c|c|}
\hline \multirow{3}{*}{ Parts } & \multicolumn{6}{|c|}{ Residual stress (MPa) } \\
\hline & \multicolumn{2}{|c|}{ Before the $\gamma$-ray irradiation } & \multicolumn{2}{|c|}{ After the $\gamma$-ray irradiation } & \multicolumn{2}{|c|}{ Variation } \\
\hline & Buffered fiber & Reference fiber & Buffered fiber & Reference fiber & Buffered fiber & Reference fiber \\
\hline Center of the core & -4.3 & -16.0 & 15.3 & 8.7 & 19.6 & 24.7 \\
\hline Outer section of the core & 21.8 & 17.6 & 19.1 & 14.5 & -2.7 & -3.1 \\
\hline Buffer cladding & -3.8 & 3.5 & -2.6 & 3.3 & 1.2 & 0.2 \\
\hline Core-buffer boundary & -5.7 & -0.8 & 5.9 & -0.5 & 11.6 & 0.3 \\
\hline Inner cladding & 24.6 & - & 25.9 & - & 1.3 & - \\
\hline $\begin{array}{c}\text { Buffer-inner } \\
\text { (or outer) cladding boundary }\end{array}$ & -26.2 & -20.3 & -33.9 & -22.9 & -7.7 & -2.6 \\
\hline Outer cladding & 6.2 & 3.0 & 6.2 & 3.1 & 0 & 0.1 \\
\hline Outermost cladding & -24.3 & -20.3 & -21.6 & -18.9 & 2.7 & 1.4 \\
\hline
\end{tabular}

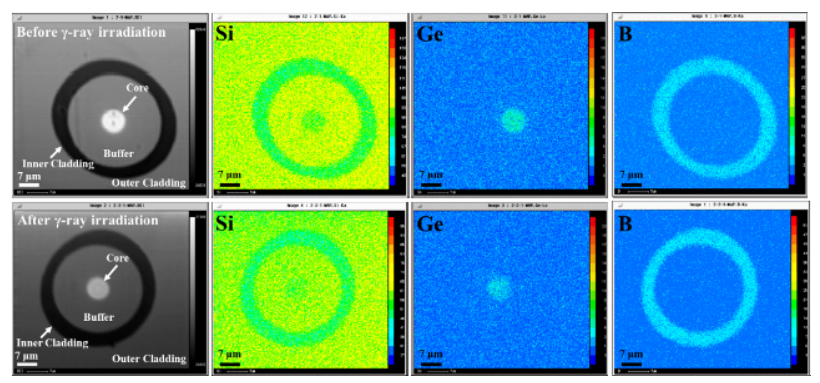

Fig. 4 EPMA based images with mapping analysis of different elements in the cross section of the buffered fiber before and after the $\gamma$-ray irradiation.

The optical attenuation of the buffered and the reference fibers before and after the steady-state irradiation with ${ }^{60} \mathrm{Co} \gamma$-ray at the total dose of $22.85 \mathrm{kGy}$ in room temperature is shown in Fig. 5. Before the $\gamma$-ray irradiation, the attenuation of the buffered fiber was $0.019 \mathrm{~dB} / \mathrm{m}$ at $1550 \mathrm{~nm}$, and that of the reference fiber was $0.015 \mathrm{~dB} / \mathrm{m}$ at $1550 \mathrm{~nm}$. Note that the difference of the attenuation of both fibers was negligible because the linear power accuracy of the OSA used was $\pm 0.05 \mathrm{~dB}$. The absorption peaks appearing at around $1175 \mathrm{~nm}$ and $1200 \mathrm{~nm}$ were from the cut-off wavelength of the fibers. Note that no absorption peaks due to the $\mathrm{OH}$ ion impurities were found. After the $\gamma$-ray irradiation, the attenuation of the fibers below $800 \mathrm{~nm}$ became dramatically increased due to that the creation of structural defects associated with both $\mathrm{Si}-\mathrm{O}$ and $\mathrm{Ge}-\mathrm{O}$ bonds in glass network because the ultraviolet and visible absorption bands are well known to be generated by the broken Ge-O bonds [26, 42, 43]. The extra strong absorption bands were found to appear at around $775 \mathrm{~nm}$ and $820 \mathrm{~nm}$, due to the next high-order mode cutoff (LP21 cutoff wavelength) and the LP11 cutoff wavelength at around $1175 \mathrm{~nm}$ and $1200 \mathrm{~nm}$ increased. Broad but low absorption above $1400 \mathrm{~nm}$ increased with an increase in wavelength (the inset of Fig. 5), which may be assigned to infrared tail absorption caused by Ge-impacted STH, Ge(1), and Ge(2) defects [42, 43]. After the $\gamma$-ray irradiation, attenuations at $1550 \mathrm{~nm}$ of the buffered fiber and the reference fiber increased to $0.064 \mathrm{~dB} / \mathrm{m}$ and $0.185 \mathrm{~dB} / \mathrm{m}$, respectively. 


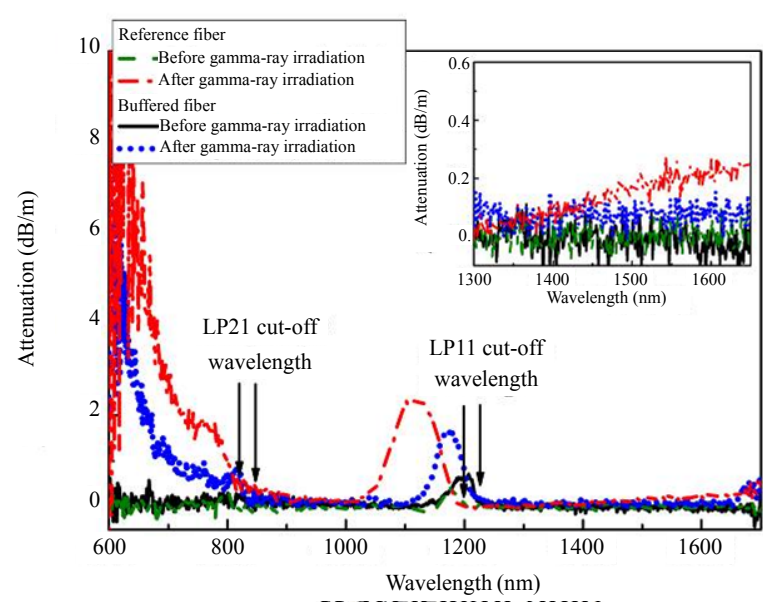

Fig. 5 Optical attenuation of the buffered and reference fibers before and after the $\gamma$-ray irradiation with the total dose of $22.85 \mathrm{kGy}$ at room temperature in air (the inset represents the magnified view the attenuation spectra from $1300 \mathrm{~nm}$ to $1650 \mathrm{~nm})$.

To investigate the effect of temperature and $\gamma$-ray irradiation on the optical power and the Bragg

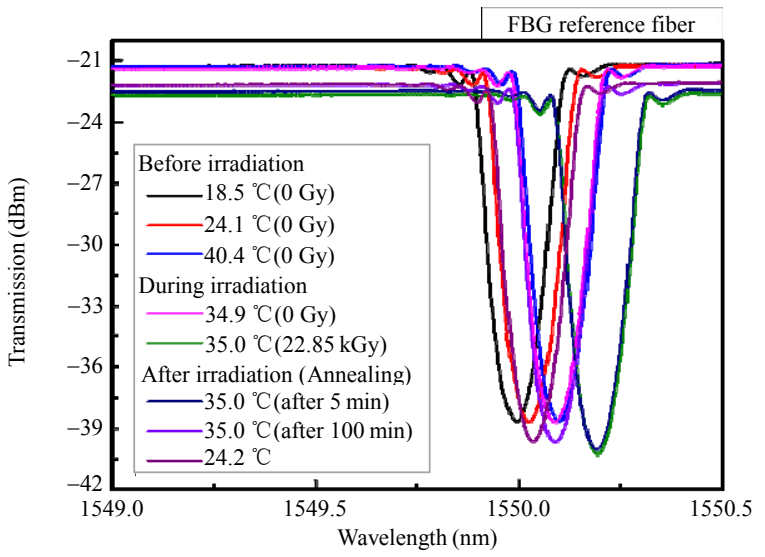

(a)

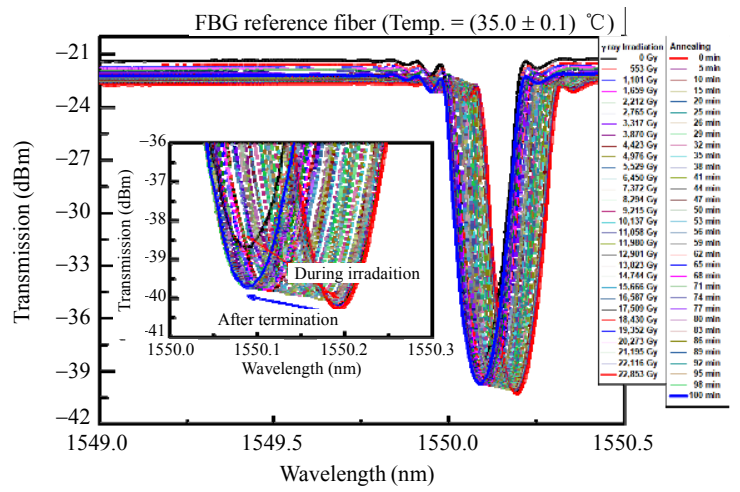

(c) wavelength shift, the optical attenuation and the Bragg reflection wavelength of FBG were measured under various temperature conditions without the $\gamma$-ray irradiation together with before, during, and after the $\gamma$-ray irradiation at temperature of $35^{\circ} \mathrm{C}$. The temperature profiles and the events of the $\gamma$-ray irradiation are shown in Fig.2(b). Figure 6 shows the transmission spectra of the FBG reference and the FBG buffered fibers upon the change in temperature and the $\gamma$-ray irradiation conditions. Note that Figs. 6(a) and 6(b) show the results of the event points upon the change in temperature and the $\gamma$-ray irradiation conditions. Figures 6(c) and 6(d) show the transmission spectra during and after the $\gamma$-ray irradiation with the dose-rate of $184.3 \mathrm{~Gy} / \mathrm{min}$ for 124 minutes at $35{ }^{\circ} \mathrm{C}$. The Bragg reflection

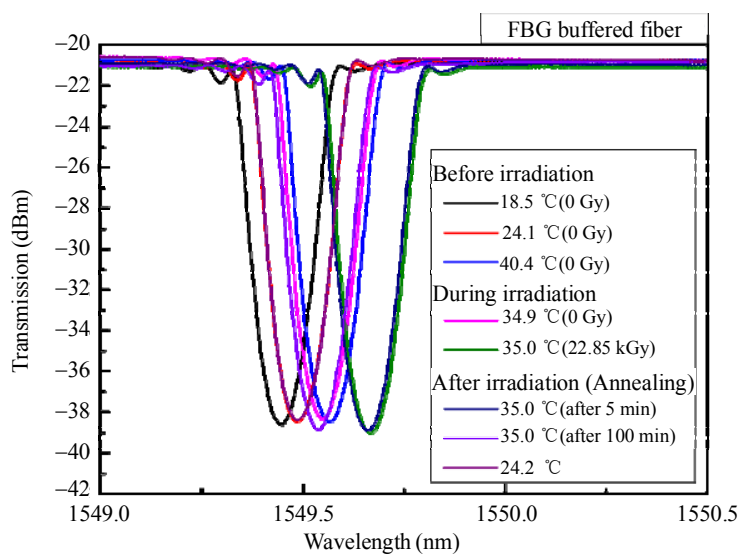

(b)

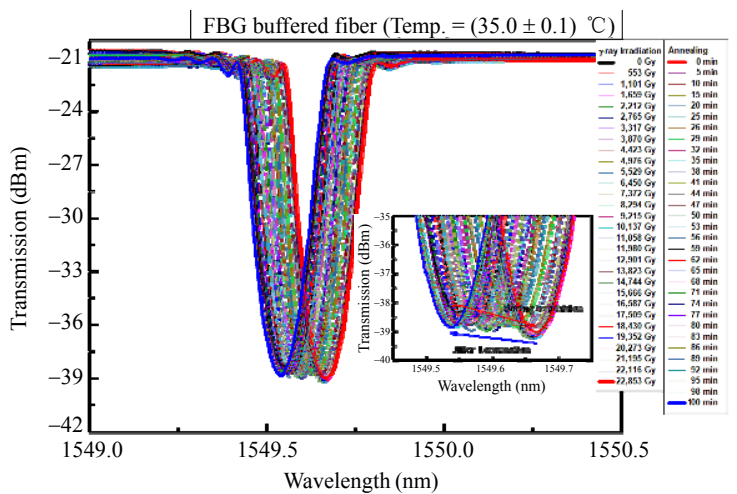

(d)

Fig. 6 Transmission spectra upon the change in temperature and the $\gamma$-ray irradiation conditions of (a) the FBG reference fiber, (b) the FBG buffered fiber and those during and after the $\gamma$-ray irradiation with the total dose of $22.85 \mathrm{kGy}$ at $35^{\circ} \mathrm{C}$ conditions, (c) the FBG reference fiber, and (d) the FBG buffered fiber. 
wavelength, the full width at half maximum (FWHM) bandwidth, the reflected peak power, and the transmission power at $1550.5 \mathrm{~nm}$ of the FBG buffered fiber before the irradiation were $1549.45 \mathrm{~nm}, 0.16 \mathrm{~nm}, 17.82 \mathrm{~dB}$, and $-20.74 \mathrm{dBm}$, respectively. And those of the FBG reference fiber, were $1550.00 \mathrm{~nm}, 0.15 \mathrm{~nm}, 17.43 \mathrm{~dB}$, and $-21.16 \mathrm{dBm}$, respectively. To test the stabilization with time of $\mathrm{FBG}$ at $35 \pm 0.1{ }^{\circ} \mathrm{C}$, the transmission power at $1550.5 \mathrm{~nm}$ and the Bragg wavelength shift were measured without the $\gamma$-ray irradiation, which almost remained constant for 15 minutes with $8.67 \times 10^{-4} \mathrm{dBm} / \mathrm{min}$ and $2.12 \times 10^{-4} \mathrm{~nm} / \mathrm{min}$, respectively. The FBG reference fiber also showed good stabilities of them to be $14.91 \times 10^{-4} \mathrm{dBm} / \mathrm{min}$ and $4.13 \times 10^{-4} \mathrm{~nm} / \mathrm{min}$, respectively.

From the results of transmission spectra

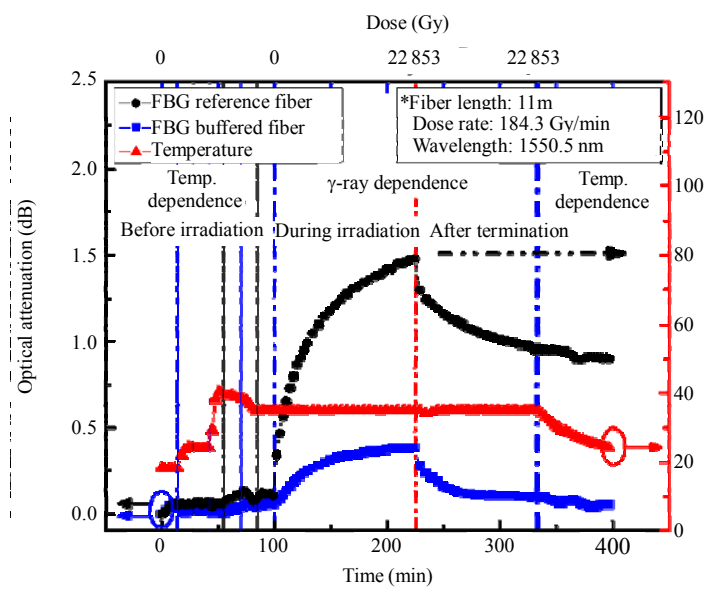

(a)

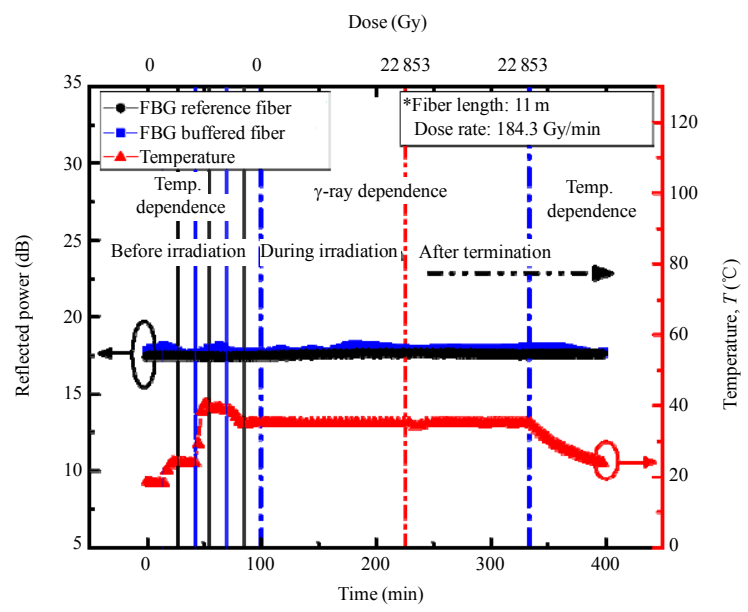

(c) measurement as shown in Fig. 6, the effects of temperature change and $\gamma$-ray irradiation with the total dose of $22.85 \mathrm{kGy}$ at $35{ }^{\circ} \mathrm{C}$ on optical power and the Bragg reflection wavelength of FBG were summarized in Figs. 7 and 8. The optical attenuation and the Bragg wavelength of FBG mainly depended on the external temperature and dose-rate of the $\gamma$-ray irradiation, respectively, as shown in Figs.7(a) and 7(b). However, as shown in Figs. 7(c) and 7(d), the reflection power of the Bragg wavelengths and the FWHM bandwidths remained with $17.86 \pm 0.33 \mathrm{dBm}$ and $0.16 \pm 0.01 \mathrm{~nm}$ for the FBG buffered fiber and $17.54 \pm 0.14 \mathrm{dBm}$ and $0.15 \pm 0.01 \mathrm{~nm}$ for the FBG reference fiber under temperature change from $18{ }^{\circ} \mathrm{C}$ to $40{ }^{\circ} \mathrm{C}$ and during and after the $\gamma$-ray irradiation with the dose-rate of $184.3 \mathrm{~Gy} / \mathrm{min}$ for 124 minutes at $35^{\circ} \mathrm{C}$, respectively.

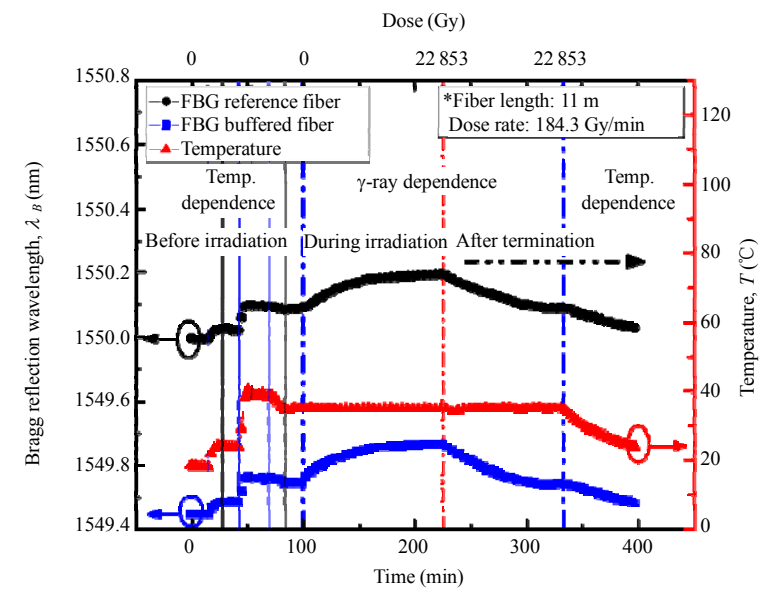

(b)

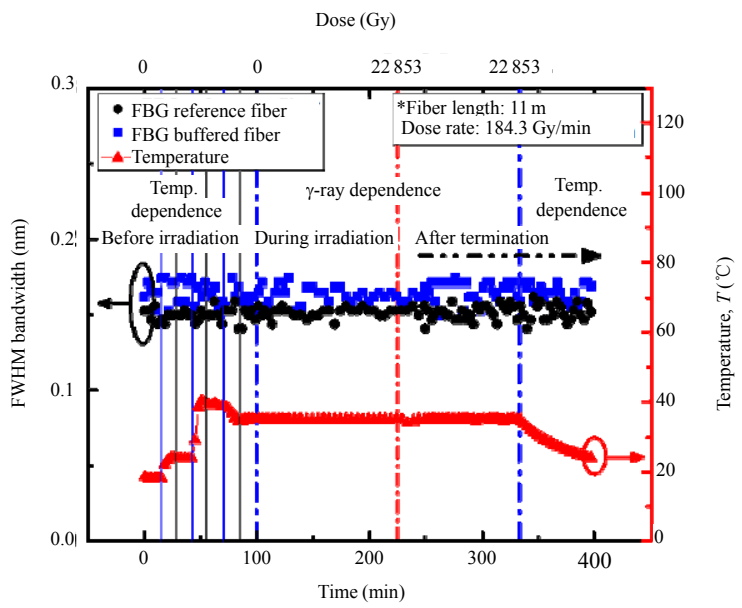

(d)

Fig. 7 Variations of (a) the optical attenuation, (b) the Bragg reflection wavelength, (c) the reflected power, and (d) FWHM bandwidth of the FBG fibers upon the change in temperature and the $\gamma$-ray irradiation conditions. 
With an increase in temperature from $18{ }^{\circ} \mathrm{C}$ to $40{ }^{\circ} \mathrm{C}$ before the $\gamma$-ray irradiation, the optical attenuation and the Bragg wavelength of FBG were found to increase and shift toward longer wavelength [Figs. 8(a) and 8(b)]. However, the extent of the attenuation increase by the temperature change was much smaller than that by the $\gamma$-ray irradiation as shown in Fig. 7(a). The extents of the

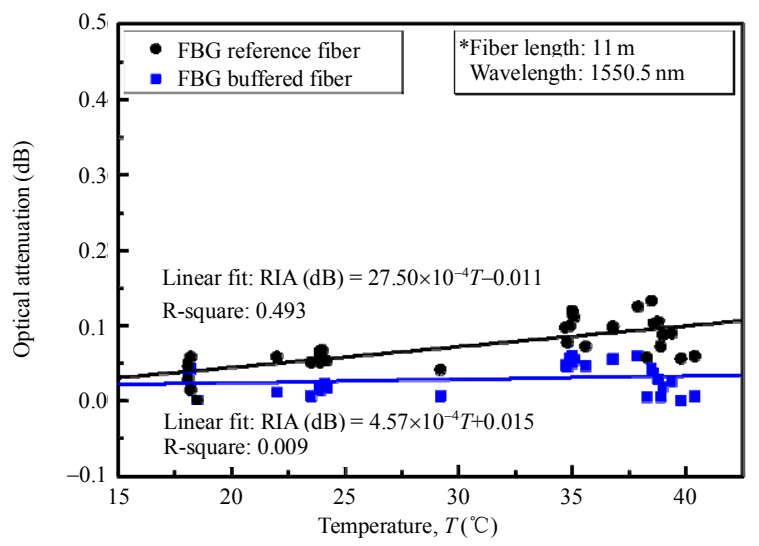

(a)

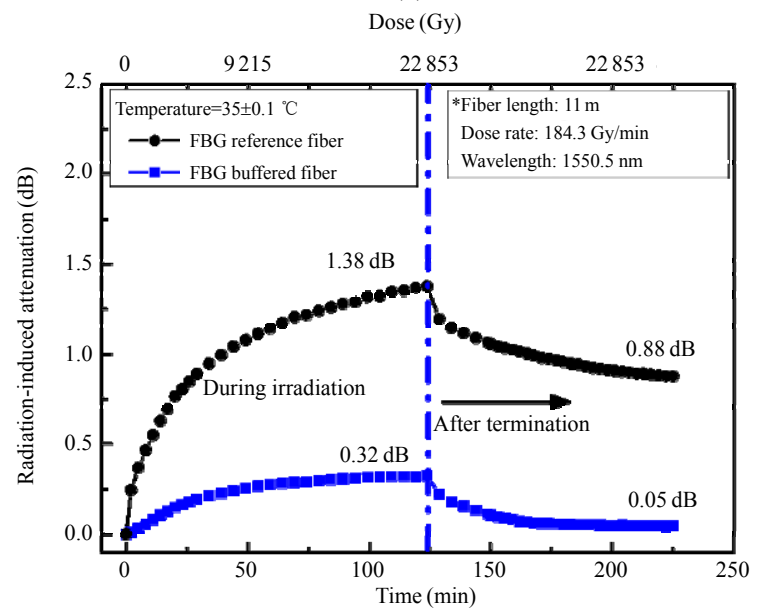

(c) attenuation increase and the Bragg wavelength shift by the temperature change from $18{ }^{\circ} \mathrm{C}$ to $40{ }^{\circ} \mathrm{C}$ before the $\gamma$-ray irradiation were about $4.57 \times 10^{-4} \mathrm{~dB} /{ }^{\circ} \mathrm{C}$ and $5.48 \mathrm{pm} /{ }^{\circ} \mathrm{C}$ with an error range of $4.9 \%$ and $0.9 \%$, respectively. In the case of the FBG reference fiber, they were about $27.50 \times 10^{-4} \mathrm{~dB} /{ }^{\circ} \mathrm{C}$ and $5.06 \mathrm{pm} /{ }^{\circ} \mathrm{C}$ with error range of $12.2 \%$ and $1.2 \%$, respectively [Figs. $8(\mathrm{a})$ and $8(b)]$.

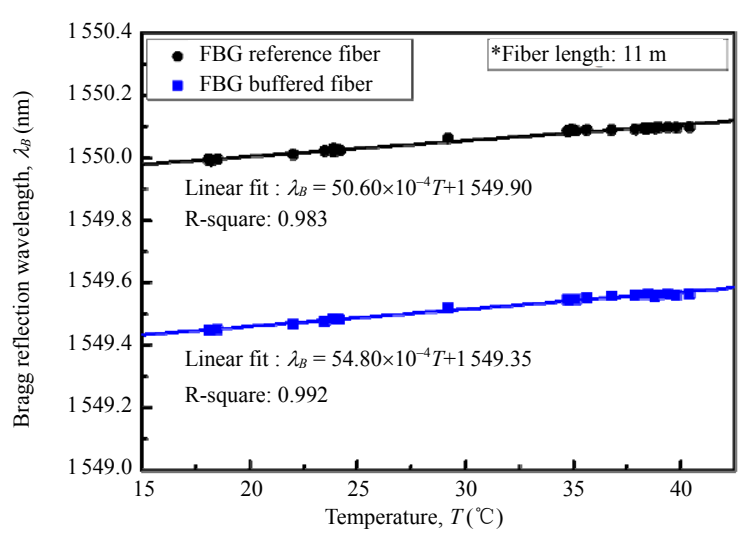

(b)

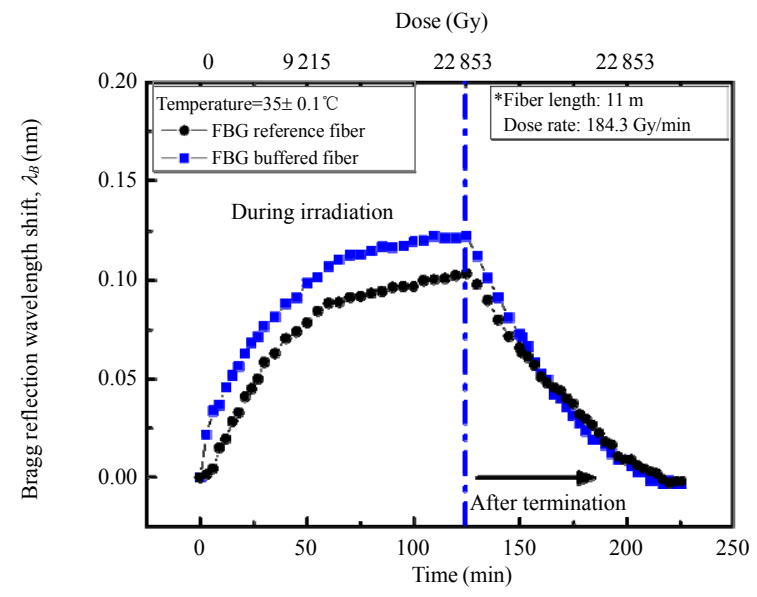

(d)

Fig. 8 Variations of (a) the optical attenuation, (b) the Bragg reflection wavelength shift of the FBG fibers from $18{ }^{\circ} \mathrm{C}$ to $40{ }^{\circ} \mathrm{C}$ before the $\gamma$-ray irradiation, (c) the radiation-induced attenuation, and (d) the Bragg reflection wavelength of the FBG fibers during and after the $\gamma$-ray irradiation with the total dose of $22.85 \mathrm{kGy}$ at $35{ }^{\circ} \mathrm{C}$.

As for the effect of the $\gamma$-ray irradiation, both RIA and Bragg wavelength increased with an increase in $\gamma$-ray irradiation from 0 to $22.85 \mathrm{kGy}$ at $35{ }^{\circ} \mathrm{C}$ as shown in Figs. 8(c) and 8(d). The RIA and the Bragg wavelength of FBG during and after the $\gamma$-ray irradiation at the total dose of $22.85 \mathrm{kGy}$ clearly indicate the $\gamma$-ray irradiation dependence. As the $\gamma$-ray irradiation increased from 0 to $22.85 \mathrm{kGy}$, the reflection power of the Bragg wavelengths was found to increase from $17.69 \mathrm{~dB}$ to $17.92 \mathrm{~dB}$ for the FBG buffered fiber and $17.48 \mathrm{~dB}$ to $17.64 \mathrm{~dB}$ for the FBG reference fiber. In addition, the transmissions at $1550.5 \mathrm{~nm}$ were found to decrease from $-20.80 \mathrm{dBm}$ to $-21.12 \mathrm{dBm}$ for the 
FBG buffered fiber and $-21.16 \mathrm{dBm}$ to $-22.64 \mathrm{dBm}$ for the FBG reference fiber. The RIAs of the FBG buffered fiber and the reference fiber of 11 meters were about $0.32 \mathrm{~dB}(0.03 \mathrm{~dB} / \mathrm{m})$ and $1.48 \mathrm{~dB}(0.13 \mathrm{~dB} / \mathrm{m})$ with the deviation of $5.3 \%$ and $6.6 \%$, respectively. The Bragg reflection wavelengths also shifted toward longer wavelengths from $1549.55 \mathrm{~nm}$ to $1549.67 \mathrm{~nm}$ for the FBG buffered fiber and from $1550.09 \mathrm{~nm}$ to $1550.20 \mathrm{~nm}$ for the FBG reference fiber during the $\gamma$-ray irradiation without changing temperature. The RIBRW shifts of the FBG buffered fiber and the reference fiber were about $5.25 \times 10^{-3} \mathrm{pm} / \mathrm{Gy}$ and $4.81 \times 10^{-3} \mathrm{pm} / \mathrm{Gy}$ with the deviation of $0.9 \%$ and $0.7 \%$, respectively. Furthermore, with an increase in the $\gamma$-ray irradiation dose, the RIAs at $1550.5 \mathrm{~nm}$ and the Bragg reflection wavelengths became saturated. From the results as shown in Figs. 8(c) and 8(d), the
RIA at $1550.5 \mathrm{~nm}$ and the Bragg reflection wavelength shift have clearly shown the dose-rate dependence.

After terminating the $\gamma$-ray irradiation at $22.85 \mathrm{kGy}$, the RIA at $1550.5 \mathrm{~nm}$ and the Bragg reflection wavelength became recovered. Also, the RIA was found to become partially recovered to $0.04 \mathrm{~dB}$ for the FBG buffered fiber and $0.95 \mathrm{~dB}$ for the FBG reference fiber after the $\gamma$-ray irradiation. However, the Bragg reflection wavelengths were completely recovered to $1549.54 \mathrm{~nm}$ for the FBG buffered fiber and $1550.09 \mathrm{~nm}$ for the FBG reference fiber after terminating the $\gamma$-ray irradiation. The reflection power of the Bragg wavelengths was $17.99 \mathrm{~dB}$ for the FBG buffered fiber and $17.52 \mathrm{~dB}$ for the FBG reference fiber. Detailed specifications of the FBG fibers before, during, and after the $\gamma$-ray irradiation are listed in Table 2.

Table 2 Optical properties of the FBG fibers during and after the $\gamma$-ray irradiation.

\begin{tabular}{|c|c|c|c|c|c|c|c|c|}
\hline & & $\begin{array}{l}\text { Temp. } \\
\left({ }^{\circ} \mathrm{C}\right) \\
\end{array}$ & $\begin{array}{l}\text { Bragg reflection } \\
\text { wavelength }(\mathrm{nm})\end{array}$ & $\begin{array}{c}\text { FWHM } \\
\text { bandwidth (nm) }\end{array}$ & $\begin{array}{c}\text { Reflected } \\
\text { peak power }(\mathrm{dB})\end{array}$ & $\begin{array}{c}\text { Transmission at } \\
1550.5 \mathrm{~nm}(\mathrm{dBm})\end{array}$ & $\begin{array}{c}\text { RIA at } \\
1550.5 \mathrm{~nm}(\mathrm{~dB} / \mathrm{m})\end{array}$ & $\begin{array}{l}\text { RIBRW } \\
\text { shift (nm) }\end{array}$ \\
\hline \multirow{3}{*}{$\begin{array}{c}\text { FBG } \\
\text { buffered fiber }\end{array}$} & $\begin{array}{l}\text { Before irradiation } \\
(0 \mathrm{~Gy})\end{array}$ & \multirow{3}{*}{$35.0 \pm 0.1$} & 1549.55 & 0.164 & 17.69 & -20.80 & \multirow{3}{*}{0.03} & \multirow{3}{*}{0.12} \\
\hline & $\begin{array}{c}\text { After irradiation } \\
(22.85 \mathrm{kGy}) \\
\end{array}$ & & 1549.67 & 0.163 & 17.92 & -21.12 & & \\
\hline & $\begin{array}{l}100 \text { minutes after the } \\
\text { termination }\end{array}$ & & 1549.54 & 0.163 & 17.99 & -20.84 & & \\
\hline \multirow{3}{*}{$\begin{array}{c}\text { FBG } \\
\text { reference fiber }\end{array}$} & $\begin{array}{c}\text { Before } \\
\text { irradiation (0 Gy) } \\
\end{array}$ & \multirow{3}{*}{$35.0 \pm 0.1$} & 1550.09 & 0.152 & 17.48 & -21.16 & \multirow{3}{*}{0.13} & \multirow{3}{*}{0.11} \\
\hline & $\begin{array}{c}\text { After irradiation } \\
(22.85 \mathrm{kGy})\end{array}$ & & 1550.20 & 0.151 & 17.64 & -22.64 & & \\
\hline & $\begin{array}{l}100 \text { minutes after the } \\
\text { termination }\end{array}$ & & 1550.09 & 0.152 & 17.52 & -22.11 & & \\
\hline
\end{tabular}

Figure 9 shows the $\gamma$-ray radiation sensitivities on the Bragg reflection wavelength shift during the irradiation by re-plotting the results before the saturation of the RIBRW up to $11.1 \mathrm{kGy}$ in Fig. 8(d). The RIBRW almost linearly increased up to $11.1 \mathrm{kGy}$ but the shift of the Bragg wavelength of both the FBG buffered fiber and the reference fiber seemed to saturate over the dose of $11.1 \mathrm{kGy}$. The $\gamma$-ray dependences of the Bragg wavelength of the FBG buffered fiber and the reference fiber up to $11.1 \mathrm{kGy}$ at dose-rate of $184.3 \mathrm{~Gy} / \mathrm{min}$ for 60 minutes were about $8.41 \times 10^{-3} \mathrm{pm} / \mathrm{Gy}$ and $8.52 \times 10^{-3} \mathrm{pm} / \mathrm{Gy}$ with error range of $2.4 \%$ and $0.9 \%$, respectively.
Dose (Gy)

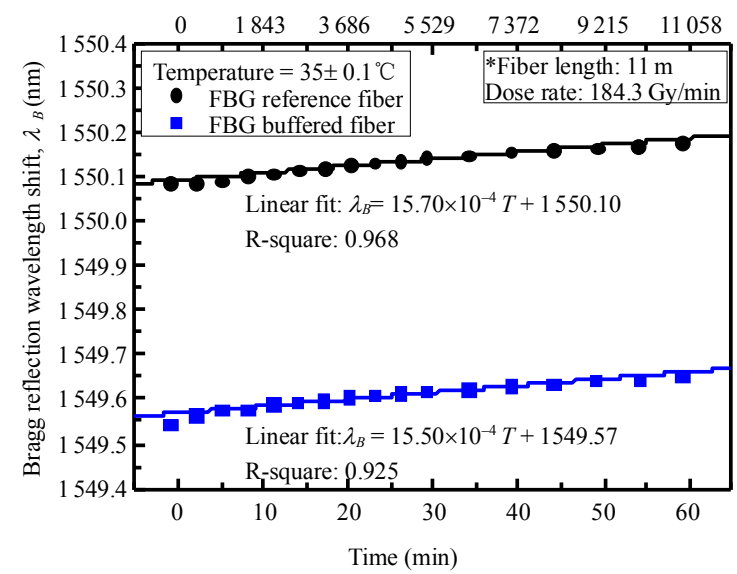

Fig. 9 Variations of the Bragg reflection wavelength with the $\gamma$-ray irradiation up to $11 \mathrm{kGy}$ at $35^{\circ} \mathrm{C}$. 


\section{Discussion}

From the results of the refractive index modulation before and after the $\gamma$-ray irradiation, the effect of the refractive index change of the fiber on the RIA and the RIBRW change was negligible because the changed refractive index was recovered to the initial state. Also, the total dose of $22.85 \mathrm{kGy}$ was not enough to change the refractive index permanently. Note that the refractive index of Geand $\mathrm{N}$-doped silica glass under the $\gamma$-ray irradiation even up to $7 \mathrm{MGy}$ increased very little by a value of greater than $10^{-4}$ in the optical transparency window [44]. In the case of the residual stress in the buffered fiber as shown in Fig.3(b), it is well recognized that the total residual stress was built up from the superposition of the thermal stress caused by a difference in the thermal expansion coefficient of the different layers and the mechanical stress induced by a difference in the viscoelastic properties during the cooling of a fiber in the drawing process $[45,46]$. The compressive stress in the center of the core $(-4.3 \mathrm{MPa})$ was induced by the mechanical stress resulted from a decrease in viscosity due to the addition of $\mathrm{GeO}_{2}$. The tensile stress in the outer cladding (6.2 MPa) was due to its relatively high viscosity. While the tensile stress in the outer cladding was induced by the external pulling force during the drawing of the fiber, the compressive stress in the outermost cladding part $(-24.3 \mathrm{MPa})$ of the fiber was induced to balance the forces after removing the drawing tension. On the other hand, the tensile stress in the inner cladding (24.6 MPa) was induced by the addition of $\mathrm{B}$ as a dopant, due to the positive thermal expansion coefficient of the inner cladding [38, 46, 47]. To minimize inevitable residual stress in the fiber core due to its different volume expansions, the buffer of a pure silica glass was also added between the core and the inner cladding. The pure silica buffer $(-3.8 \mathrm{MPa})$ showed the small compression stress as a result of the mechanical stress [47]. The tensile stress in the outer section of the core $(21.8 \mathrm{MPa})$ was from the thermal stress induced by the difference in thermal expansion coefficients between the core and the buffer cladding [45]. And the core-buffer cladding boundary $(-5.7 \mathrm{MPa})$ was under the compressive stress induced by the mechanical stress due to the difference in the viscoelastic properties of the different regions during the cooling of the fiber in the fiber drawing process. The compressive stress at the boundary $(-26.2 \mathrm{MPa})$ between the buffer and the inner cladding was caused by the presence of $\mathrm{OH}$ impurity penetrated in during the jacketing process. Note that to fabricate the present complicated preform, the germano-silicate glass core rod with the pure silica glass buffer made from the OVD process was jacketed with the fused silica glass tube deposited with the B-doped silica glass as the inner cladding made from the MCVD process [48].

After the $\gamma$-ray irradiation, the compressive stresses formed in the center of the core, the buffer cladding and the outermost cladding part of the buffered fiber were relaxed, and the tensile stress inside of the B-doped inner cladding increased slightly. While no change of the residual stress in the outer cladding was found, the tensile stresses formed in the outer section of the core and on the inner cladding were relaxed and increased slightly, respectively. However, the compressive stress induced by $\mathrm{OH}$ impurity at the buffer cladding-inner cladding boundary increased because of an increase in absorption due to $\mathrm{OH}$ groups with the $\gamma$-ray irradiation [49]. Note that as the compressive stresses in the center of the core and at the core-buffer cladding boundary changed to tension, the tensile stress around the center of the core was relaxed after the $\gamma$-ray irradiation as shown in the inset of Fig. 3(b). In the case of the residual stress of the reference fiber, the compressive stresses in the core and at the core-buffer boundary were induced by the mechanical stress and the difference in the viscoelastic properties of the different regions, 
respectively. Similar to the results of the buffered fiber, the tensile stress still remained in the outer cladding due to the external pulling force during the drawing process and the compressive stress in the outermost cladding. After the $\gamma$-ray irradiation, the compressive stress in the outermost cladding slightly increased due to an increase in absorption from $\mathrm{OH}$ groups like that of the buffered fiber [31,32]. While no changes of tensile stresses in the buffer and the outer cladding, and compressive stress in the core-buffer boundary were found, the compressive stress in the center of the core changed to tensile stress from -16.0 MPa to 8.7 MPa.

From the results of EPMA measurement as shown in Fig. 4, the presences of $\mathrm{GeO}_{2}$ and $\mathrm{B}$ in the optical fiber core and the cladding, respectively, were clearly distinguished. However, no appreciable changes in the distribution of $\mathrm{GeO}_{2}$ and $\mathrm{B}$ were found before and after the $\gamma$-ray irradiation. Moreover, as can be seen from the measured refractive index profile and the EPMA based images, the core diameter and the widths of the buffer and depressed-index cladding measured by the EPMA were a little different from those of the refractive index profile because of the different resolution of the two methods. Therefore, any change in concentrations of $\mathrm{GeO}_{2}$ and $\mathrm{B}$ was impossible to examine before and after the $\gamma$-ray irradiation, due to the resolution limit of the EPMA.

After the $\gamma$-ray irradiation with the total dose of $22.85 \mathrm{kGy}$ at room temperature $\left(18{ }^{\circ} \mathrm{C}\right)$ in air, the optical absorption of the fibers below $800 \mathrm{~nm}$ dramatically increased due to $\mathrm{NBOHC}$ ( $\equiv \mathrm{O}-\mathrm{Si}$ at $185 \mathrm{~nm}, 260 \mathrm{~nm}$, and $620 \mathrm{~nm})$ and $\mathrm{E}^{\prime}$ center ( $\equiv \mathrm{Si}$ at $215 \mathrm{~nm}$ ) due to strained $\mathrm{Si}-\mathrm{O}$ bonds as well as the creation of structural defects associated with Ge-O bonds [3, 43, 50-52]. The optical absorption in the wavelength region from $1400 \mathrm{~nm}$ to $1650 \mathrm{~nm}$ due to the infrared tail absorption increased with an increase in the wavelength in both the buffered and reference fibers after the irradiation. From the optical attenuation before and after the steady-state irradiation with ${ }^{60} \mathrm{Co} \gamma$-ray at the total dose of $22.85 \mathrm{kGy}$ as shown in Fig. 5, the attenuation at $1550 \mathrm{~nm}$ of the buffered fiber and the reference fiber increased from $0.019 \mathrm{~dB} / \mathrm{m}$ to $0.064 \mathrm{~dB} / \mathrm{m}$ and from $0.015 \mathrm{~dB} / \mathrm{m}$ to $0.185 \mathrm{~dB} / \mathrm{m}$, respectively. Lower generation of the Ge-related defects such as STHs, $\mathrm{Ge}(1)$, and $\mathrm{Ge}(2)$ in the buffered fiber may have contributed to the radiation hardening at $1550 \mathrm{~nm}$ as shown in Fig. 7(a). By this reason, even though the Ge-doped silica glass core fiber showed poor radiation hardening compared with the pure silica glass core fiber, the present buffered fiber based on the Ge-doped silica glass core was fabricated by applying pure silica glass buffer and B-doped silica glass inner cladding.

Regarding the photosensitivity of the Ge-doped silica glass core fiber, the core refractive index can be permanently modified due to the generation of $\mathrm{GeE}^{\prime}$ centers from germanium in the fiber core by UV irradiation. The UV-induced refractive index change is responsible for the formation of FBG [53].

The variation of the transmission power at $1550.5 \mathrm{~nm}$ and the Bragg wavelength shift of the FBG fibers with time at $35 \pm 0.1{ }^{\circ} \mathrm{C}$ without the $\gamma$-ray irradiation were almost constant for 15 minutes. In addition, during the temperature variation from $18{ }^{\circ} \mathrm{C}$ to $40{ }^{\circ} \mathrm{C}$, the temperature dependence of optical attenuation in the FBG buffered fiber was about 6 times lower than that of the FBG reference fiber within the optical power fluctuation as shown in Fig. 8(a). In the case of the shift of the Bragg reflection wavelength, both fibers have shown a tendency similar to the temperature change and the Bragg reflection wavelength was linearly shifted with an increase in temperature as known from the results in Fig. 8(b). The temperature dependences of the Bragg reflection wavelength shift in both FBG fibers have almost similar values.

Under the $\gamma$-ray irradiation with the dose-rate of $184.3 \mathrm{~Gy} / \mathrm{min}$ for 124 minutes at $35{ }^{\circ} \mathrm{C}$, the change of the Bragg reflection wavelength, the reflected peak power, and the transmission power at 
$1550.5 \mathrm{~nm}$ of the FBG buffered fiber were $0.12 \mathrm{~nm}$, $0.23 \mathrm{~dB}$, and $0.32 \mathrm{~dB}$, with an increase in the $\gamma$-ray irradiation from 0 to $22.85 \mathrm{kGy}$ for 124 minutes, respectively. However, in the case of the FBG reference fiber for a comparison, the change of the Bragg reflection wavelength, the reflected peak power, and the transmission power at $1550.5 \mathrm{~nm}$ became large to be $0.11 \mathrm{~nm}, 0.16 \mathrm{~dB}$, and $1.48 \mathrm{~dB}$, respectively. The $\gamma$-ray irradiation dependences of optical attention in the FBG buffered fiber $(R I A=$ $0.03 \mathrm{~dB} / \mathrm{m}$ ) was about 4 times smaller than that in the FBG reference fiber $(R I A=0.13 \mathrm{~dB} / \mathrm{m})$ at a total dose of $22.85 \mathrm{kGy}$ due to the lower optical absorption above $1400 \mathrm{~nm}$. However, the $\gamma$-ray irradiation dependences of the Bragg reflection wavelength shift were also similar about $5.25 \times 10^{-3} \mathrm{pm} / \mathrm{Gy}$ for the FBG buffered fiber and about $4.81 \times 10^{-3} \mathrm{pm} / \mathrm{Gy}$ for the FBG reference fiber at a total dose of $22.85 \mathrm{kGy}$. Our results of the temperature sensitivity $\left(5.48 \mathrm{pm} /{ }^{\circ} \mathrm{C}\right)$ and the $\gamma$-ray radiation sensitivity $\left(5.25 \times 10^{-3} \mathrm{pm} / \mathrm{Gy}\right)$ on the Bragg reflection wavelength shift during the irradiation in the FBG buffered fiber was similar to the previous results of the commercial FBG fiber (temperature sensitivity: about $10 \mathrm{pm} /{ }^{\circ} \mathrm{C}$ and $\gamma$-ray radiation sensitivity: about $0.1 \mathrm{pm} / \mathrm{kGy}-10 \mathrm{pm} / \mathrm{kGy}[10,12$, 13, 15, 37]. Therefore, the effect of temperature increase on the Bragg reflection wavelength was about 1000 times tremendously larger than that of the $\gamma$-ray irradiation, clearly demonstrating the feasibility as a temperature sensor under $\gamma$-ray irradiation environment.

The shift of the Bragg reflection wavelength was saturated at a level of about $0.10 \mathrm{~nm}$ for the FBG buffered fiber and about $0.09 \mathrm{~nm}$ for the FBG reference fiber after a dose of $11.1 \mathrm{kGy}$ and then slightly increased about $0.02 \mathrm{~nm}$ and $0.02 \mathrm{~nm}$, respectively during the $\gamma$-ray irradiation up to a dose of $22.85 \mathrm{kGy}$. The $\gamma$-ray irradiation dependences of the Bragg reflection wavelength shift of both the fibers were more similar up to cumulative dose of $11.1 \mathrm{kGy}$ than those up to $22.85 \mathrm{kGy}$. Therefore, the
B-doped inner cladding layers in the FBG buffered fiber were not affected significantly on the temperature and the $\gamma$-ray irradiation.

It is well known that the temperature dependence of FBG is mainly related to the thermal expansion and the thermal-optic effect of the fiber glass with temperature and the $\gamma$-ray irradiation dependence is due to the change in the effective core refractive index caused by radiation $[37,54,55]$. Therefore, a decrease in transmission power and the shift of the Bragg reflection wavelength of the $\gamma$-ray irradiated FBG fibers were due to the formation of the radiation-induced defects and color centers and an increase in the reflective index, respectively $[5,13$, $14,22]$.

The loss recovery ratios of the FBG buffered fiber and the reference fiber measured at 100 minutes after terminating the $\gamma$-ray irradiation were $84.4 \%$ and $36.2 \%$, respectively. This loss recovery may be due to the rehabilitating process of the radiation-induces defects. However, the Bragg reflection wavelengths of both FBG fibers were completely recovered due to the relaxation of the physical parameters caused by the temperature change.

The measured $\gamma$-ray irradiation resistance depended on the layer of the B-doped silica glass inner cladding in the fiber, reducing STH defects and minimizing the formation of defect centers such as the BOHCs and boron $\mathrm{E}^{\prime}$ center $[56,57]$. Note that when $\mathrm{B}$ was present in the optical fiber core, it acted as an impurity and was affected by the primary RIA. However, when B existed in the cladding, it did not affect the RIA to increase directly but it affected the light interaction characteristics at the interface between the core and the outer cladding for radiation hardening $[58,59]$. Also, the presence of $\mathrm{B}$ in the depressed-index inner cladding increased light transmission by increasing the evanescent field coupling due to the change in the refractive index by the $\gamma$-ray irradiation [60]. Therefore, the present fibers were not significantly affected by a fiber 
bending because the depressed B-doped silica glass inner cladding enhanced the bend-insensitivity [29]. In addition, the layer of the pure silica glass buffer blocked an increase in the formation of defect centers under the $\gamma$-ray irradiation. Moreover, the pure silica glass buffer minimized the formation of residual stress in the fiber core due to different thermal properties of glasses with different compositions [4-8, 10, 14-26].

After terminating the $\gamma$-ray irradiation at $22.85 \mathrm{kGy}$, which was taken 100 minutes after the end of irradiation, the Bragg reflection wavelength of FBG became fully recovered and remained a constant. This result is consistent with the fact of no change in the refractive index after the $\gamma$-ray irradiation as shown in Fig. 3(a).

\section{Conclusions}

A new radiation-hard germano-silicate glass optical fiber with the pure silica glass buffer and the B-doped silica glass inner cladding was fabricated by using the OVD and the MCVD processes for fiber sensor applications in harsh nuclear environments. To investigate the effect of temperature and $\gamma$-ray irradiation on optical attenuation, FBG was inscribed on the fiber and its wavelength shift was measured at various temperatures. After the $\gamma$-ray irradiation with a total dose of $22.85 \mathrm{kGy}$ at $18{ }^{\circ} \mathrm{C}$ in air, no significant change in the refractive index was found. And the residual stresses in most layers of the fiber were slightly relaxed or retained. Especially, the compressive stresses in the center of the core and at the core-buffer cladding boundary had changed to tension after the $\gamma$-ray irradiation.

The optical attenuation at $1550 \mathrm{~nm}$ of the buffered fiber was about 3 times smaller than that of the reference fiber due to the lower generation of Ge-related defects such as STHs, $\mathrm{Ge}(1)$, and $\mathrm{Ge}(2)$. With an increase in temperature from $18^{\circ} \mathrm{C}$ to $40{ }^{\circ} \mathrm{C}$ before the $\gamma$-ray irradiation, the temperature dependences of optical attenuation at $1550.5 \mathrm{~nm}$ and
Bragg reflection wavelength shift of the FBG buffered fiber were about $4.57 \times 10^{-4} \mathrm{~dB} /{ }^{\circ} \mathrm{C}$ and $5.48 \mathrm{pm} /{ }^{\circ} \mathrm{C}$, respectively. Under the $\gamma$-ray irradiation from 0 to $22.85 \mathrm{kGy}$ for 124 minutes at $35^{\circ} \mathrm{C}$, the RIA and the RIBRW shift of the 11-meter-long FBG buffered fiber were about $0.32 \mathrm{~dB}(0.03 \mathrm{~dB} / \mathrm{m})$ and $0.12 \mathrm{~nm}$, respectively. The $\gamma$-ray irradiation dependence of the Bragg wavelength shift of the FBG buffered fiber was about $5.25 \times 10^{-3} \mathrm{pm} / \mathrm{Gy}$. However, no significant change in the reflection power of the Bragg wavelengths and the FWHM bandwidth under temperature and the $\gamma$-ray irradiation change were found.

The $\gamma$-ray irradiation sensitivity of the FBG buffered fiber was about $8.41 \times 10^{-3} \mathrm{pm} / \mathrm{Gy}$ under the dose-rate of $184.3 \mathrm{~Gy} / \mathrm{min}$ up to $11.1 \mathrm{kGy}$ at $35^{\circ} \mathrm{C}$. After terminating the $\gamma$-ray irradiation at $22.85 \mathrm{kGy}$, the RIA at $1550.5 \mathrm{~nm}$ and the Bragg reflection wavelength became recovered. The loss recovery ratios at 100 minutes after terminating the $\gamma$-ray irradiation of the FBG buffered fiber was about $84.4 \%$, while the Bragg reflection wavelengths were completely recovered.

\section{Acknowledgment}

We thank the Advanced Technology Radiation Laboratory of the Korea Atomic Energy Research Institute for their assistance with $\gamma$-ray irradiation measurements. This work was partially supported by the Korea Electric Power Corporation Research Institute (Grant No. KEPRI-16-23) and the Korea Industrial Complex Corporation Industrial Cluster Competitiveness Enhancement Project (Grant No. RGJ18014), South Korea.

Open Access This article is distributed under the terms of the Creative Commons Attribution 4.0 International License (http://creativecommons.org/licenses/by/4.0/), which permits unrestricted use, distribution, and reproduction in any medium, provided you give appropriate credit to the original author(s) and the source, provide a link to the Creative Commons license, and indicate if changes were made. 


\section{References}

[1] J. Shah, "Effects of environmental nuclear radiation on optical fibers," Bell System Technical Journal, 1975, 54(7): 1207-1213.

[2] E. J. Friebele, C. G. Askins, M. E. Gingerich, and K. J. Long, "Optical fiber waveguides in radiation environments, II," Nuclear Instruments and Methods in Physics Research Section B: Beam Interactions With Materials and Atoms, 1984, 1(2-3): 355-369.

[3] S. Girard, J. Kuhnhenn, A. Gusarov, B. Brichard, M. Van Uffelen, Y. Ouerdane, et al., "Radiation effects on silica-based optical fibers: recent advances and future challenges," IEEE Transactions on Nuclear Science, 2013, 60(3): 2015-2036.

[4] H. Henschel, O. Köhn, H. U. Schmidt, E. Bawirzanski, and A. Landers, "Optical fibres for high radiation dose environments," IEEE Transactions on Nuclear Science, 1994, 41(3): 510-516.

[5] A. Iino and J. Tamura, "Radiation resistivity in silica optical fibers," Journal of Lightwave Technology, 1998, 6(2): 145-149.

[6] T. Shikama, T. Kakuta, M. Narui, T. Sagawa, N. Shamoto, T. Uramoto, et al., "Behavior of radiation-resistant optical fibers under irradiation in a fission reactor," Journal of Nuclear Materials, 1994, 212-215(1): 421-425.

[7] A. Honda, K. Toh, S. Nagata, B. Tsuchiya, and T. Shikama, "Effect of temperature and irradiation on fused silica optical fiber for temperature measurement," Journal of Nuclear Materials, 2007, 1367-370(B): 1117-1121.

[8] T. Kakuta, T. Shikama, M. Narui, and T. Sagawa, "Behavior of optical fibers under heavy irradiation," Fusion Engineering and Design, 1998, 41(1-4): 201-205.

[9] M. Shan, H. Wang, Z. Xu, N. Li, C. Chen, J. Shi, et al., "Synergetic improvement of mechanical properties and surface activities in $\gamma$-irradiation carbon fibers revealed by radial positioning spectroscopy and mechanical model," Analytical Methods, 2018, 10(5): 496-503.

[10] K. O. Hill and G. Meltz, "Fiber Bragg grating technology fundamentals and overview," Journal of Lightwave Technology, 1997, 15(8): 1263-1276.

[11] S. J. Mihailov, "Fiber Bragg grating sensors for harsh environments," Sensors, 2012, 12(2): 1898-1918.

[12] A. I. Gusarov, F. Berghmans, A. F. Fernandez, O. Deparis, Y. Defosse, D. Starodubov, et al., "Behavior of fibre Bragg gratings under high total dose gamma radiation," IEEE Transactions on Nuclear Science, 2000, 47(3): 688-692.

[13] A. F. Fernandez, B. Brichard, F. Berghmans, and M. Decréton, "Dose-rate dependencies in gamma-irradiated fiber Bragg grating filters," IEEE Transactions on Nuclear Science, 2002, 49(6): 2874-2878.

[14] A. Gusarov, D. Kinet, C. Caucheteur, M. Wuilpart, and P. Mégret, "Gamma radiation induced short-wavelength shift of the Bragg peak in type I fiber gratings," IEEE Transactions on Nuclear Science, 2010, 57(6): 3775-3778.

[15] A. Gusarov, S. Vasiliev, O. Medvedkov, I. Mckenzie, and F. Berghmans, "Stabilization of fiber Bragg gratings against gamma radiation," in Proceeding of 2007 9th European Conference on Radiation and Its Effects on Components and Systems, Deauville, France, 2007.

[16] K. Fujita, A. Kimura, M. Nakazawa, and H. Takahashi, "Bragg peak shifts of fiber Bragg gratings in radiation environment," in Proceedings of SPIE 4204, Fiber Optic Sensor Technology II, Boston, MA, USA, 2000, pp: 184-191.

[17] D. Grobnic, H. Henschel, S. K. Hoeffgen, J. Kuhnhenn, S. J. Mihailov, and U. Weinand, "Radiation sensitivity of Bragg gratings written with femtosecond IR lasers," in Proceedings of SPIE 7316, Fiber Optic Sensors and Applications VI, Orlando, Florida, USA, 2009, pp: 73160C-1-73160C-9.

[18] S. K. Hoeffgen, H. Henschel, J. Kuhnhenn, U. Weinand, C. Caucheteur, D. Grobnic, et al., "Comparison of the radiation sensitivity of fiber Bragg gratings made by four different manufacturers," IEEE Transactions on Nuclear Science, 2011, 58(3): 906-909.

[19] H. Henschel, S. K. Hoeffgen, J. Kuhnhenn, and U. Weinand, "Influence of manufacturing parameters and temperature on the radiation sensitivity of fiber Bragg gratings," IEEE Transactions on Nuclear Science, 2010, 57(4): 2029-2034.

[20] H. Henschel, D. Grobnic, S. K. Hoeffgen, J. Kuhnhenn, S. J. Mihailov, and U. Weinand, "Development of highly radiation resistant fiber Bragg gratings," IEEE Transactions on Nuclear Science, 2011, 58(4): 2103-2110.

[21] S. M. Eaton, H. Zhang, P. R. Herman, F. Yoshino, L. Shah, J. Bovatsek, et al., "Heat accumulation effects in femtosecond laser-written waveguides with variable repetition rate," Optics Express, 2005, 13(12): 4708-4716.

[22] B. D. Evans, "The role of hydrogen as a radiation protection agent at low temperature in a low-OH, pure silica optical fiber," IEEE Transactions on Nuclear Science, 1988, 35(6): 1215-1220.

[23] D. Sporea, A. Sporea, and C. Oproiu, "Effects of hydrogen loading on optical attenuation of gamma-irradiated UV fibers," Journal of Nuclear Materials, 2012, 423(1-3): 142-148.

[24] A. Alessi, S. Girard, M. Cannas, S. Agnello, A. Boukenter, and Y. Ouerdane, "Influence of drawing 
conditions on the properties and radiation sensitivities of pure-silica-core optical fibers," Journal of Lightwave Technology, 2012, 30(11): 1726-1732.

[25] A. L. Tomashuk and M. O. Zabezhailov, "Formation mechanisms of precursors of radiation-induced color centers during fabrication of silica optical fiber preform," Journal of Applied Physics, 2011, 109(8): 083103-1-083103-11.

[26] K. Nagasawa, Y. Hoshi, Y. Ohki, and K. Yahagi, "Improvement of radiation resistance of pure silica core fibers by hydrogen treatment," Japanese Journal of Applied Physics, 1985, 24(9): 1224-1228.

[27] G. H. Sigel Jr., E. J. Friebele, and M. E. Gingerich, "Recent progress in the investigation of radiation resistant optical fibers," in Proceedings of SPIE 0296, Fiber Optics in Adverse Environments I, 25th Annual Technical Symposium, San Diego, USA, Jan. $1-8,1982$.

[28] K. Sanada, T. Shamoto, and K. Inada, "Radiation resistance characteristics of graded-index fibers with a core of Ge-, F-doped or B and F-codoped $\mathrm{SiO}_{2}$ glass," Journal of Non-Crystalline Solids, 1995, 189(3): 283-290.

[29] P. R. Watekar, S. Ju, and W. T. Han, "Design and development of a trenched optical fiber with ultra-low bending loss," Optics Express, 2009, 17(12): 10350-10363.

[30] B. Brichard, O. V. Butov, K. M. Golant, and A. F. Fernandez, "Gamma radiation-induced refractive index change in Ge- and N-doped silica," Journal of Applied Physics, 2008, 103(5): 054905-1-054905-4.

[31] K. Sanada, N. Shamoto, and K. Inada, "Radiation resistance of fluorine-doped silica-core fibers," Journal of Non-Crystalline Solids, 1994, 179(4): 339-344.

[32] E. J. Friebele, D. L. Griscom, and G. H. Sigel Jr., "Defect centers in a germanium-doped silica-core optical fiber," Journal of Applied Physics, 1974, 45(8): 3424-3428.

[33] S. Ju, Y. Kim, S. Jeong, J. Y. Kim, N. H. Lee, H. K. Jung, et al., "Gamma-ray dose-rate dependence on radiation resistance of specialty optical fiber with inner cladding layers," Springer Proceedings in Physics, 2016, 177: 51-65.

[34] N. P. Bansal and R. H. Doremus, "Handbook of glass properties," Orlando, Florida, USA: Academic Press, 1986: 548-551.

[35] J. W. Yu and K. Oh, "New in-line fiber band pass filters using high silica dispersive optical fibers," Optics Communications, 2002, 204(1-6): 111-118.

[36] H. Hultzsch, Eds., Optical telecommunication systems. Damm-Verlag KGGelsenkirchen, Germany: Academic Press, 1996.

[37] S. Ju, P. R. Watekar, and W. T. Han, "Enhanced sensitivity of the FBG temperature sensor based on the $\mathrm{PbO}-\mathrm{GeO}_{2}-\mathrm{SiO}_{2}$ glass optical fiber," Journal of
Lightwave Technology, 2010, 28(18): 2697-2700.

[38] P. L. Chu and T. Whitbread, "Measurement of stresses in optical fiber and preform," Applied Optics, 1982, 21(23): 4241-4245.

[39] Y. Park, S. Choi, U. C. Paek, K. Oh, and D. Y. Kim, "Measurement method for profiling the residual stress of an optical fiber: detailed analysis of off-focusing and beam-deflection effects," Applied Optics, 2003, 42(7): 1182-1190.

[40] C. Yin, X. Hanning, G. Weiming, and G. Wenming, "Thermal behavior of $\mathrm{GeO}_{2}$ doped $\mathrm{PbO}-\mathrm{B}_{2} \mathrm{O}_{3}-\mathrm{ZnO}-\mathrm{Bi}_{2} \mathrm{O}_{3}$ glasses," Materials Science and Engineering: A, 2006, 423(1-2): 184-188.

[41] J. J. Shyu, C. Y. Lue, and R. D. Jean, "Addition of $\mathrm{GeO}_{2}$ to reduce the viscosity of parent glasses for low-expansion, transparent glass-ceramics containing high-quartz solid solutions," Journal of the American Ceramic Society, 2006, 89(10): 3235-3239.

[42] M. Kyoto, Y. Chigusa, M. OOE, M. Watanabe, T. Matubara, T. Yamamoto, et al., "Gamma-ray irradiation effect on loss increase of single mode optical fibers, (I) loss increase behavior and kinetic study," Journal of Nuclear Science and Technology, 1989, 26(5): 507-515.

[43] E. Regnier, I. Flammer, S. Girard, F. Gooijer, F. Achten, and G. Kuyt, "Low-dose radiation-induced attenuation at infrared wavelengths for P-doped, Ge-doped and pure silica-core optical fibres," IEEE Transactions on Nuclear Science, 2007, 54(4): 1115-1119.

[44] B. Brichard, O. V. Butov, K. M. Golant, and A. F. Fernandez, "Gamma radiation-induced refractive index change in Ge- and N-doped silica," Journal of Applied Physics, 2008, 103(5): 054905-1-054905-4.

[45] B. H. Kim, T. J. Ahn, D. Y. Kim, B. H. Lee, Y. Chung, U. C. Paek, et al., "Effect of $\mathrm{CO}_{2}$ laser irradiation on the refractive-index change in optical fibers," Applied Optics, 2002, 41(19): 3809-3815.

[46] B. H. Kim, Y. Park, T. J. Ahn, D. Y. Kim, B. H. Lee, Y. Chung, et al., "Residual stress relaxation in the core of optical fiber by $\mathrm{CO}_{2}$ laser irradiation," Optics Letters, 2001, 26(21): 1657-1659.

[47] C. S. Kim, Y. Han, B. H. Lee, W. T. Han, U. C. Paek, and Y. Chung, "Induction of the refractive index change in B-doped optical fibers through relaxation of the mechanical stress," Optics Communications, 2000, 185(4-6): 337-342.

[48] B. H. Kim, Y. Park, D. Y. Kim, U. C. Paek, and W. T. Han, "Observation and analysis of residual stress development resulting from $\mathrm{OH}$ impurity in optical fibers," Optics Letter, 2002, 27(10): 806-808.

[49] F. H. El Batal, "Gamma ray interaction with bismuth silicate glasses," Nuclear Instruments and Methods in Physics Research Section B: Beam Interactions With Materials and Atoms, 2007, 254(2): 243-253.

[50] Y. Kim, S. Ju, S. Jeong, S. H. Lee, and W. T. Han, 
"Gamma-ray radiation response at $1550 \mathrm{~nm}$ of fluorine-doped radiation hard single-mode optical fiber," Optics Express, 2016, 24(4): 3910-3920.

[51] G. Origlio, A. Boukenter, S. Girard, N. Richard, M. Cannas, R. Boscaino, et al., "Irradiation induced defects in fluorine doped silica," Nuclear Instruments and Methods in Physics Research Section B: Beam Interactions With Materials and Atoms, 2008, 266(12-13): 2918-2922.

[52] K. Kajihara, M. Hirano, L. Skuja, and H. Hosono, ${ }^{" 60} \mathrm{Co} \gamma$-ray-induced intrinsic defect processes in fluorine-doped synthetic $\mathrm{SiO}_{2}$ glasses of different fluorine concentrations," Materials Science and Engineering: B, 2009, 161(1-3): 96-99.

[53] J. H. Jang, J. Koo, and B. S. Bae, "Photosensitivity of germanium oxide and germanosilicate glass sol-gel films," Journal of Non-Crystalline Solids, 1999, 259(1-3): 144-148.

[54] J. E. Shelby, "Effect of radiation on the physical properties of borosilicate glasses," Journal of Applied Physics, 1980, 51(5): 2561-2565.

[55] A. Morana, S. Girard, E. Marin, C. Marcandella, J. Périsse, J. R. Macé, et al., "Radiation hardening of FBG in harsh environments," in Proceedings of SPIE 9157, 23rd International Conference on Optical Fiber Sensors, Santander, Spain, Jun., 2014, pp: 91578I-1-91578I-4.
[56] G. H. Sigel Jr., E. J. Friebele, and M. E. Gingerich, "Recent progress in the investigation of radiation resistant optical fibers," in Proceedings of SPIE 0296, Conference on Fiber Optics in Adverse Environments I, 25 ${ }^{\text {th }}$ Annual Technical Symposium, San Diego, CA, USA, Jan. 1-8, 1982.

[57] S. Girard, J. Keurinck, Y. Ouerdane, J. P. Meunier, and A. Boukenter, "Gamma-rays and pulsed X-ray radiation responses of germanosilicate single-mode optical fibers: Influence of cladding codopants," Journal of Lightwave Technology, 2004, 22(8): 1915-1922.

[58] J. E. Golob, P. B. Lyons, and L. D. Looney, "Transient radiation effects in low-loss optical waveguides," IEEE Transactions on Nuclear Science, 1977, NS-24(6): 2164-2168.

[59] S. Ju, P. R. Watekar, Y. T. Ryu, Y. Lee, S. G. Kang, Y. Kim, et al., "Fabrication and gamma-ray irradiation effect on optical and mechanical properties of germano-silicate glass fibers with inner cladding of $\mathrm{B}$ and $\mathrm{F}$ doped silica glasses," Fiber and Integrated Optics, 2019, 38(4): 191-207.

[60] F. Liu, Y. An, P. Wang, B. Shao, and S. Chen, "Effects of radiation on optical fibers," Recent Progress in Optical Fiber Research, M. Yasin, Eds., InTech, Shanghai, China: Academic Press, 2012: 431-450. 